\title{
Carpal tunnel syndrome caused by neural fibrolipoma
}

Daiji Uchiyama, ${ }^{1}$ Toshihisa Oshige, ${ }^{2}$ Katsumi Nakamura, ${ }^{1}$ Masamichi Koganemaru ${ }^{3}$

${ }^{1}$ Department of Radiology, Tobata Kyoritsu Hospital, Kitakyushu, Japan

${ }^{2}$ Department of Orthopaedic Surgery, Tobata Kyoritsu Hospital, Kitakyushu, Japan ${ }^{3}$ Department of Radiology, Kurume University School of Medicine, Kurume, Japan

\section{Correspondence to}

Dr Masamichi Koganemaru, mkoganemaru@med.kurume-u. ac.jp

Accepted 15 December 2015
CrossMark

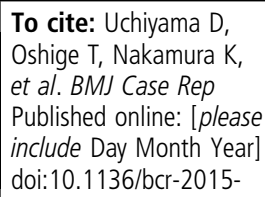

\section{DESCRIPTION}

A 45-year-old woman presented with progressive right hand numbness in the area of distribution of the median nerve, and inadequate thumb opposition. On physical examination, a soft elastic mass was noted on the distal volar aspect of her forearm (figure 1, dot circle), with an atrophy of the thenar eminence (figures 1 and 2, red circle). Phalen's test

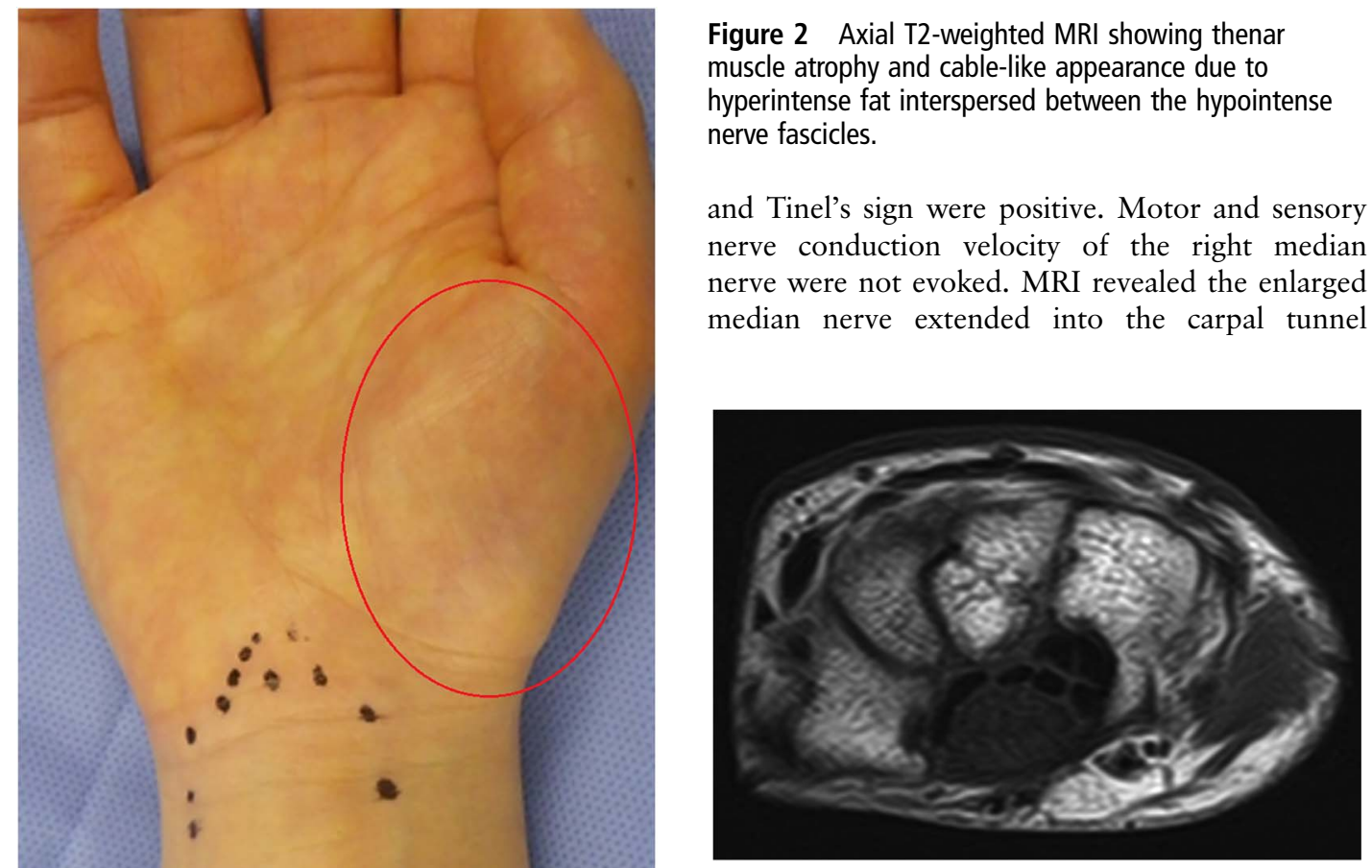

Figure 3 Axial T1-weighted MRI showing enlarged median nerve.

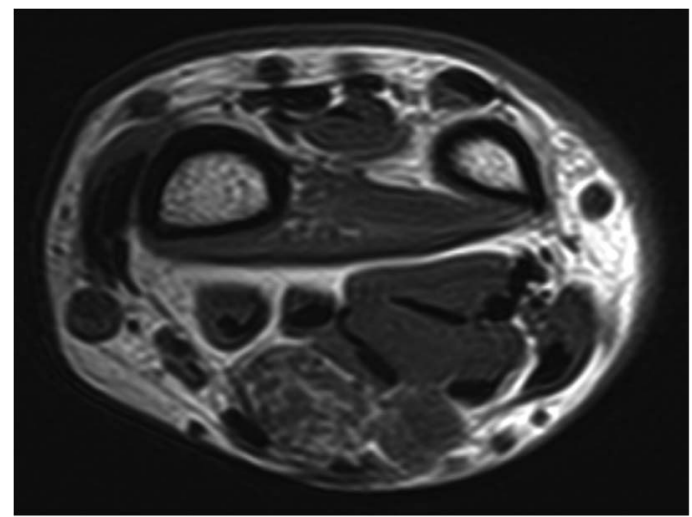

Figure 4 Axial T1-weighted MRI showing enlarged median nerve with coaxial cable-like appearance due to hyperintense fat interspersed between the hypointense nerve fascicles. 


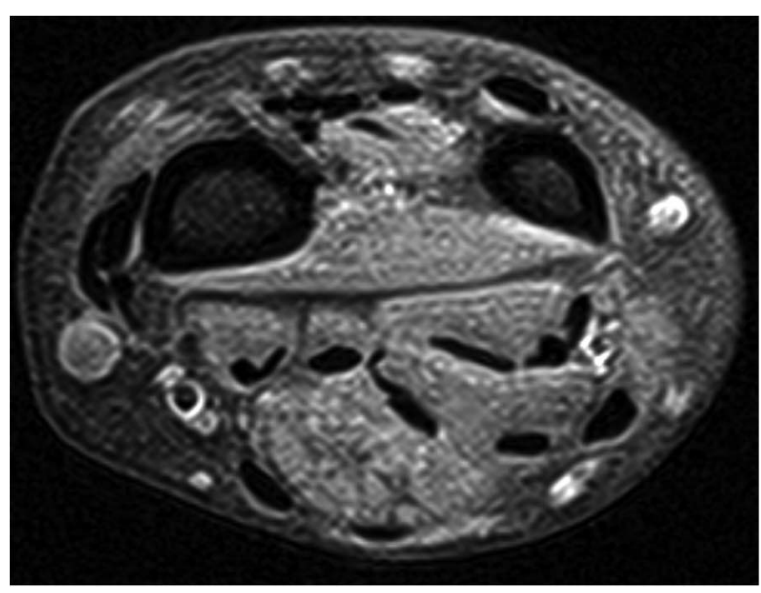

Figure 5 Fat suppression proton density weighted axial image showing low signal lesions with suppression of the predominant adipose component.

(figures 2-4). The characteristic 'coaxial cable-like' appearance was observed on T1-weighted and T2-weighted axial images (figures 2 and 4), in which the intermingled reticular high signals were decreased in the fat suppression proton density weighted axial image (figure 5), which indicated the lesion included diffuse fatty infiltration. The 'spaghetti-like' appearance in the fat suppression proton density weighted coronal image was shown (figure 6). The carpal tunnel syndrome due to neural fibrolipoma of the right median nerve was diagnosed,

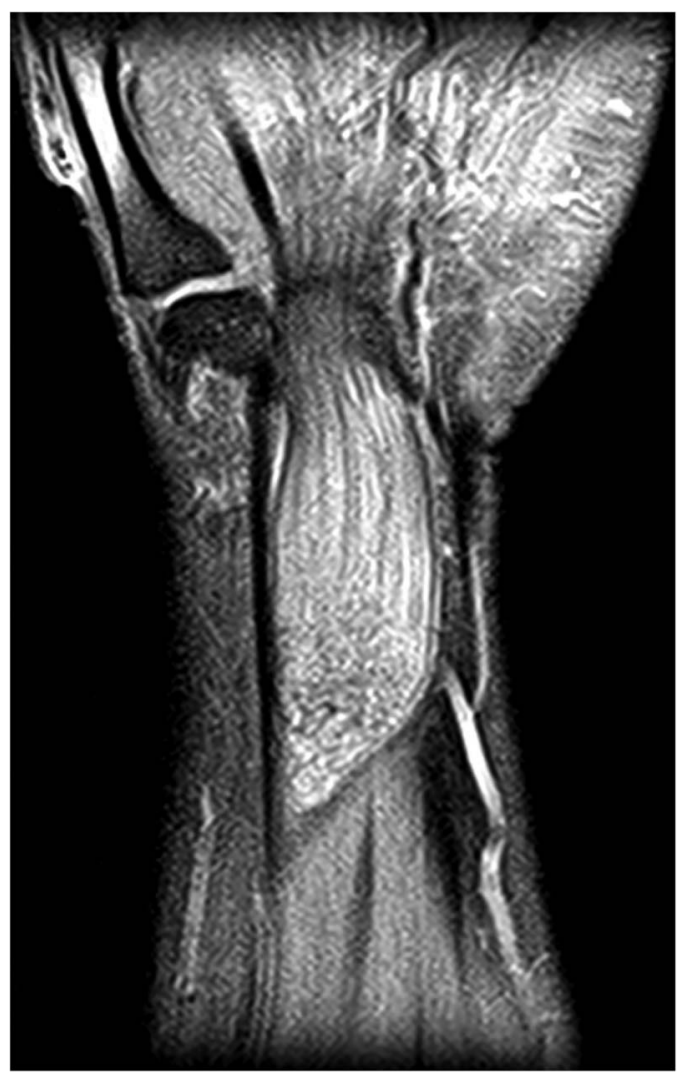

Figure 6 Fat suppression proton density weighted coronal image showing hyperintense linear median nerve fibres in hypointense fat, giving a spaghetti-like appearance.

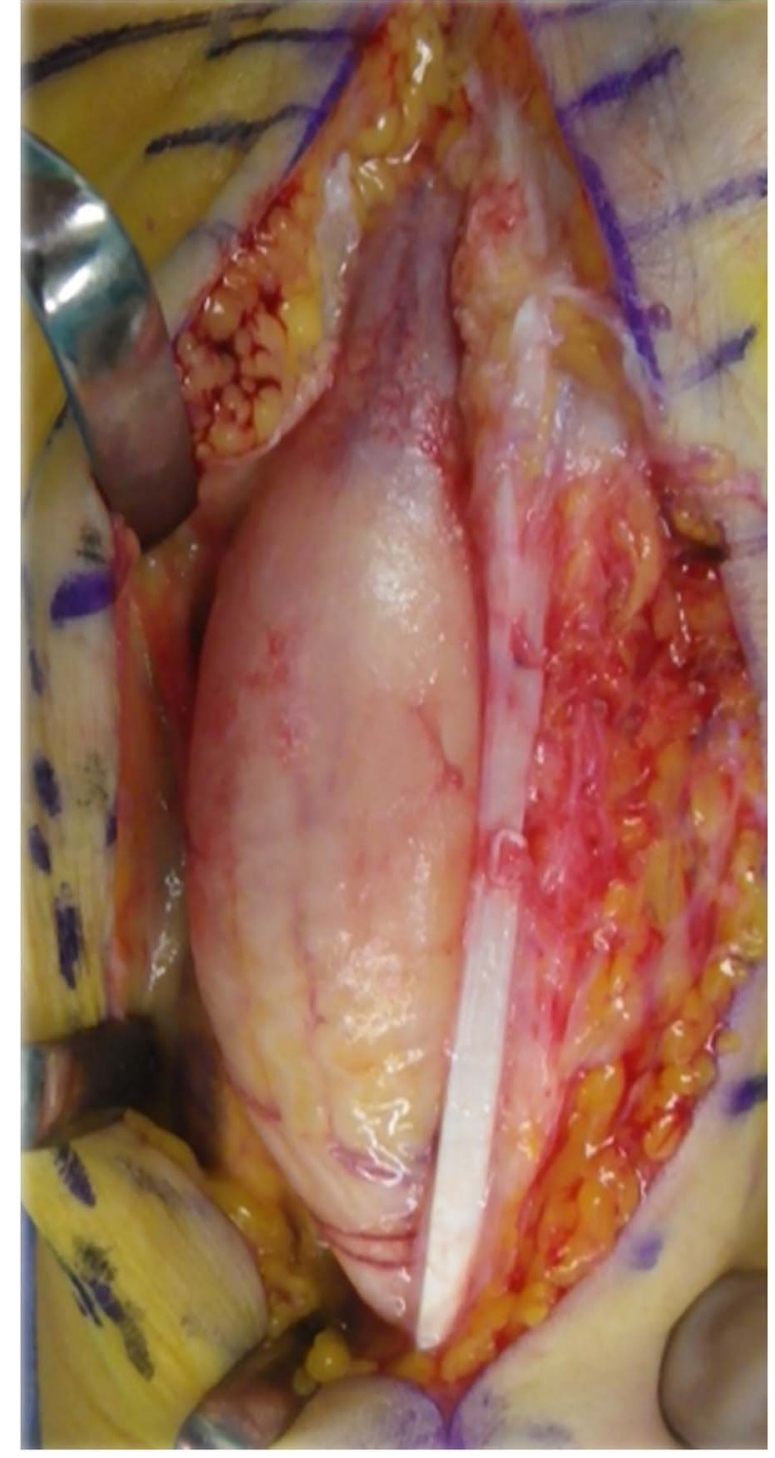

Figure 7 Operative findings showing a fusiform enlarged median nerve.

then a carpal tunnel release operation was performed. On surgical exploration, a $6 \times 2 \mathrm{~cm}$ fusiform enlarged median nerve was observed (figure 7). The patient's condition had improved at 3-month follow-up, and she now uses the hand well in her job as a cashier.

Neural fibrolipoma, also called fibrolipomatous hamartoma, was first described in 1953 by Mason. ${ }^{1}$ Although 22-67\% of cases were reported to be associated with macrodactyly, or macrodystrophia lipomatosa if it was present at birth, ${ }^{2}$ the patients had no macrodactyly. The relationship between neural fibrolipoma and macrodystrophia lipomatosa is not clear. ${ }^{2}$

This disease is a comparatively rare benign tumour that most often involves the median nerve, however, we must keep in mind the characteristic MRI findings. ${ }^{2}$ The differential diagnosis of fusiform nerve enlargement includes neural fibrolipoma, lipoma within the nerve sheath and plexiform neurofibroma. In this case, MRI revealed characteristic nerve fascicles surrounded and separated by fibrous and fatty tissue within the expanded nerve sheath as typical features of neural fibrolipoma, which could clearly be distinguished from other disease. MRI may lead to accurate diagnosis and obviate unnecessary biopsy. ${ }^{2} 3$ 
Treatment is still controversial. Careful preoperative planning is necessary for the optimal treatment based on the clinical and radiological findings.

\section{Learning points}

- MRI of neural fibrolipoma of the nerve has a characteristic 'coaxial cable-like' appearance on axial image and a 'spaghetti-like' display on coronal image.

- MRI may obviate the need for biopsy for diagnosis.
Competing interests None declared.

Patient consent Obtained.

Provenance and peer review Not commissioned; externally peer reviewed.

\section{REFERENCES}

1 Mason ML. Presentation of cases: proceedings of the American Society for Surgery of the Hand. J Bone Joint Surg 1953;35:273-4.

2 Chiang CL, Tsai MY, Chen CK. MRI diagnosis of fibrolipomatous hamartoma of the median nerve and associated macrodystrophia lipomatosa. I Chin Med Assoc 2010;73:499-502.

3 Okubo T, Saito T, Mitomi H, et al. Intraneural lipomatous tumor of the median nerve: three case reports with a review of literature. Int I Surg Case Rep 2012;3:407-11.

Contributors DU, TO and KN evaluated the patient, diagnosed the condition and carried out the treatment. All the authors were involved in collecting data, searching the literature and final approval of the article.

Copyright 2016 BMJ Publishing Group. All rights reserved. For permission to reuse any of this content visit http://group.bmj.com/group/rights-licensing/permissions.

BMJ Case Report Fellows may re-use this article for personal use and teaching without any further permission.

Become a Fellow of BMJ Case Reports today and you can:

- Submit as many cases as you like

- Enjoy fast sympathetic peer review and rapid publication of accepted articles

- Access all the published articles

- Re-use any of the published material for personal use and teaching without further permission

For information on Institutional Fellowships contact consortiasales@bmjgroup.com

Visit casereports.bmj.com for more articles like this and to become a Fellow 